\title{
Trust in God: an evaluative review of the literature and research proposal
}

\author{
Joshua N. Hook, Daryl R. Van Tongeren, Don E. Davis, Peter C. Hill, M. \\ Elizabeth Lewis Hall, Daniel J. McKaughan \& Daniel Howard-Snyder
}

To cite this article: Joshua N. Hook, Daryl R. Van Tongeren, Don E. Davis, Peter C. Hill, M. Elizabeth Lewis Hall, Daniel J. McKaughan \& Daniel Howard-Snyder (2021): Trust in God: an evaluative review of the literature and research proposal, Mental Health, Religion \& Culture, DOI: 10.1080/13674676.2021.1939291

To link to this article: https://doi.org/10.1080/13674676.2021.1939291

曲 Published online: 04 Aug 2021.

Submit your article to this journal ¿

Q View related articles ¿

View Crossmark data ¿ 


\section{Trust in God: an evaluative review of the literature and research proposal}

Joshua N. Hook ${ }^{a}$, Daryl R. Van Tongeren ${ }^{b}$, Don E. Davis ${ }^{c}$, Peter C. Hill ${ }^{\text {, }}$, M. Elizabeth Lewis Hall ${ }^{d}$, Daniel J. McKaughan ${ }^{e}$ and Daniel Howard-Snyder ${ }^{f}$

${ }^{\mathrm{a}}$ Department of Psychology, University of North Texas, Denton, TX, USA; ${ }^{\mathrm{b}}$ Department of Psychology, Hope College, Holland, MI, USA; 'Department of Counseling and Psychological Services, Georgia State University,

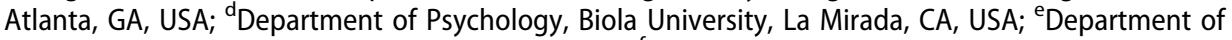
Philosophy, Boston College, Chesnut Hill, MA, USA; 'Department of Philosophy, Western Washington University, Bellingham, WA, USA

\begin{abstract}
Until recently, psychologists have conceptualised and studied trust in God (TIG) largely in isolation from contemporary work in theology, philosophy, history, and biblical studies that has examined the topic with increasing clarity. In this article, we first review the primary ways that psychologists have conceptualised and measured TIG. Then, we draw on conceptualizations of TIG outside the psychology of religion to provide a conceptual map for how TIG might be related to theorised predictors and outcomes. Finally, we provide a research agenda for future empirical work in this area, as well as practical applications for counsellors and religious leaders.
\end{abstract}

\section{ARTICLE HISTORY}

Received 11 January 2021

Accepted 1 June 2021

\section{KEYWORDS}

Trust; God; belief; reliance; expectations

The past few decades of research have evidenced a thriving body of work on the psychology of religion and spirituality $(\mathrm{R} / \mathrm{S})$. There are two primary driving forces of this movement. First, research has linked R/S to numerous positive physical and mental health outcomes, as a source of resilience, coping, and well-being rather than pathology (Garssen et al., 2021; Oman \& Syne, 2018). Second, the multicultural movement (e.g., Sue et al., 1992) has increased recognition of the importance of attending to cultural differences. Given that R/S is strongly influenced by culture (Cohen, 2009) and is a core aspect of many people's identities (Hook et al., 2012), investigators have increasingly recognised the importance of $R / S$ in cultural research. Better understanding the $R / S$ values and perspectives of individuals can provide a richer and more complete view of human functioning.

However, the overgeneralised statements about religion characteristic of early research in this area presented an obstacle to further progress, as they ignored individual variation in beliefs, behaviours, bonding, and belonging (cf. Saroglou, 2011), as well as the myriad ways that individuals engage their religion. Accordingly, definitions of R/S and its components have become more nuanced. Early on in the field, R/S was often measured using global indices such as self-rated religiousness or church attendance (Hill \& 
Pargament, 2003). Such approaches were a good first step for measuring relatively accessible indices of R/S: researchers could assess R/S using straightforward questions about religious rituals or behaviours (e.g., frequency of prayer or church attendance), or through asking participants to provide a general sense of how important R/S was in their life. However, these broad measurement approaches failed to capture the rich complexity of how R/S affects psychology and behaviour. Moreover, it obscured meaningful differences in religious individuals. Put differently, such general approaches were helpful for understanding between-group variance when comparing religious and nonreligious individuals, but there is at least as much (if not more) within-group variance among religious individuals. The wide variety of $\mathrm{R} / \mathrm{S}$ perspectives and practices predict important outcomes across a range of psychological processes and behaviours; thus, the field has developed as researchers have begun to conceptualise and measure $R / S$ more specifically. For example, researchers have explored more nuanced constructs, including constructs that focus on people's relational experience of God in addition to more traditional measures of religious salience, belief, or involvement.

One helpful extension of research on R/S is to conceptualise one's relationship with God as having similar properties, functions, and processes as interpersonal relationships. Just as other research programmes have extended features present in interpersonal relationships (e.g., attachment) to one's relationship with the divine (e.g., attachment to God; Rowatt \& Kirkpatrick, 2002), trust can be extended to one's relationship with God since trust is a central feature in interpersonal relationships (Rosmarin et al., 2009). Moreover, many major religions emphasise trust for initiating, maintaining, and repairing a relationship with God (Godfrey, 2012). So, it is not surprising that there is some interest in this area in the psychological study of religion. Furthermore, recent advances in the philosophy of trust (e.g., Faulkner \& Simpson, 2017) and the conceptualisation of Trust in God (TIG) in history, theology, and biblical studies (e.g., Morgan, 2015), suggest that revisiting this construct in the psychology of religion could lead to some productive research directions. Thus, in the present article, we aim to review how TIG has been conceptualised and measured in the psychological literature. Then, we present a conceptual model for TIG and suggest some directions for future research.

\section{Prior conceptualisation and measurement}

Only two research teams have conducted programmatic research on the psychology of TIG. Examining their definitions and measures will provide a context for comparing the psychological literature on TIG to related work in philosophy and theology.

\section{Trust in God as beliefs about God's nature and relations to humanity}

One programme of research was developed by Rosmarin and colleagues. Their measure of TIG is based on Jewish theorising (ibn Pekuda, trans. 1996), according to which TIG involves "a cognitive and affective state in which a person feels that God is taking care of their best interests" (Rosmarin et al., 2009, p. 100). However, their measure drops the affective state and focuses exclusively on the cognitive state, which they identify as believing six statements: (1) God has constant regard for all worldly affairs, (2) God has absolute knowledge of what is in people's best interests, (3) no power is greater than 
God, (4) God must be involved for anything to occur, (5) God is merciful and generous, and (6) God is righteous in judgment (Rosmarin et al., 2009). Thus, the conceptualisation of TIG they used in their measure was cognitive.

In their initial scale development effort to measure TIG, Rosmarin et al. (2009) used four items for each of the six beliefs. After scale development work and winnowing items, their work resulted in a 16-item measure with two subscales reflecting TIG (12 items; e.g., "God is never ignorant of my concerns") and mistrust in God (MIG; four items; e.g., "God disregards my activities"). Both subscales showed adequate levels of internal consistency and test-retest reliability, and were correlated in the expected direction with general religiousness, prayer, synagogue attendance, and religious study, which provided evidence for convergent validity.

Subsequent studies by Rosmarin and his team have used slightly different versions of the TIG and MIG scales. For example, Rosmarin et al. (2010) used an 11-item TIG subscale and a nine-item MIG subscale, both of which showed adequate levels of internal consistency. Rosmarin, Pirutinsky, Auerbach, et al. (2011) also developed a brief six-item measure of TIG (three items measure TIG and three items measure MIG), which again showed strong evidence for internal consistency and validity. This brief measure has been successfully used in samples of Christians (Rosmarin, Pirutinsky, \& Pargament, 2011), Jews (Krumrei et al., 2013), and Muslims (Hafizi et al., 2014).

Over time Rosmarin's (Rosmarin et al., 2010) TIG framework has become more parsimonious. According to Rosmarin's team, TIG is belief of the following three statements about God: (1) the Divine has regard for all worldly affairs (i.e., omniscience), (2) the Divine is greater than other powers/forces (i.e., omnipotence), and (3) the Divine is merciful and generous (i.e., omnibenevolence) (Rosmarin, Pirutinsky, Auerbach, et al., 2011). Elsewhere, TIG is simply "the conviction that God takes care of one's best interests" (Rosmarin et al., 2010, p. 100). MIG, in contrast, is the belief that the Divine is ignorant or malevolent. TIG and MIG are considered to be orthogonal constructs: whereas TIG involves the presence or absence of belief of core religious teachings, MIG is more closely connected to the presence or absence of spiritual struggles (Rosmarin, Pirutinsky, Auerbach, et al., 2011). The upshot is that the construct used in the measure identifies TIG with beliefs about God and God's role in the world and relation to humanity.

\section{Trust in God as expectancies of God}

A second programme of research was developed by Krause and his team (Krause, 2015a). They used Rosmarin's conceptualisation of TIG (Krause \& Hayward, 2015), but Krause emphasised two further claims (2015b). First, TIG underlies many theodicies because they involve the afterlife, which is empirically unverifiable, and so they must be taken on trust. Second, TIG increases as individuals worship together and receive consensual validation and support for their beliefs.

In addition to his work on general TIG, Krause and colleagues developed a research programme on trust-based prayer expectancies (TBPE; Krause, 2004; Krause et al., 2000). Expectancies are defined as beliefs about future states of affairs. In the context of prayer, they are beliefs about responses from God. An expectancy is trust-based when it involves, for example, believing that only God knows when it is best to answer a prayer, and only God knows the best way to answer it. In other words, people 
acknowledge that they are limited in knowing what they need, and instead trust in God's better judgment. TBPE may be more likely to be adaptive and related to positive mental health (compared to other types of expectations about prayer) because they are more difficult to disconfirm (Krause \& Hayward, 2013).

In regard to measurement, Krause and colleagues have used a five-item measure of TIG across studies (Krause, 2015b). All items are positively valenced, two represent face-valid statements about TIG, in that they reference trust directly ("I trust God completely" and "I trust God because He has always been right there for me in the past") and, similar to the Rosmarin measure, the other three items are beliefs about the benevolence of God (e.g., "I believe that God will never let me down"). This measure of TIG has shown strong levels of internal consistency across studies. To assess TBPE, Krause and colleagues have used a two-item scale (i.e., "Learning to wait for God's answer to my prayers is an important part of my faith"; "When I pray, God does not always give me what I ask for because only he knows what is best") (Krause \& Hayward, 2013). The two items show moderate to strong correlations with each other across studies (Krause \& Hayward, 2013, 2014). Most of the research using these measures has involved Christians (Krause, 2004; Krause \& Hayward, 2013); the reliability and validity of these measures are currently unknown for use with people from other religious traditions.

\section{Summary and critique}

Research on TIG is in a very early stage, with only two initial research programmes in existence. Both approaches view TIG as a mostly cognitive construct. In other words, they identify TIG with believing statements about God. Rosmarin's (Rosmarin et al., 2009) approach involves particular beliefs about God and Krause's (2015a) approach involves a mix of beliefs about God and two face-valid items about trust (which could incorporate cognitive, affective, or behavioural components). There are some key limitations in these approaches to conceptualising and measuring TIG.

First, although TIG plausibly involves some cognitive state toward statements about God, it is not at all clear that TIG must involve the cognitive state of belief that, for example, God is benevolent. There are two alternate options to consider. First, rather than, for example, believing that God is benevolent, one might accept that God is benevolent or belieflessly assume that God is benevolent. Acceptance and beliefless assuming are cognitive states, but they are not belief (Alston, 1996; Howard-Snyder, 2017). Moreover, rather than believing the "thick" statement that God is benevolent, one might believe a "thinner" statement (e.g., there's a good enough chance that God is benevolent to act on it). This first point was recognised in psychological studies of trust in business contexts: "the amount of knowledge necessary for trust is somewhere between total knowledge and total ignorance" (McAllister, 1995, p. 26; citing Simmel, 1964).

Second, TIG plausibly involves much more than cognitions about God. Indeed, the Jewish theological source of Rosmarin's (Rosmarin et al., 2009) cognitive construct (ibn Pekuda, trans. 1996) emphasises relying on God for something that matters to one, which points to motivational, emotional, and behavioural components of TIG. Furthermore, the primacy of experiential, rather than merely cognitive, understandings of TIG is suggested by developmental theory such as Erikson's (1950) work, which proposes that the capacity for trust is developed in the first two years of life-long before the 
possibility of abstract beliefs of the sort Rosmarin (Rosmarin et al., 2009) and Krause (2015a) focus on. Erikson's (1950) proposal has received support in the form of research in the attachment tradition (e.g., Rodriguez et al., 2015).

Third, simply naming the construct "TIG" may have some limitations because religions, and individuals within those religions, might vary widely in how they conceptualise trust. With respect to religious differences, both measures appear to be based on the work of Rabbi ibn Pekuda (trans. 1996), writing around 1080, although different versions of the Rosmarin et al. (2009) measure have been used with Jewish (Rosmarin et al., 2009), Christian (Rosmarin, Pirutinsky et al., 2011), and Muslim (Hafizi et al., 2014) samples. Even so, the measures omit the evident non-cognitive components of ibn Pekuda's (trans. 1996) account of TIG, notably relying on God. Furthermore, a theoretical base that draws broadly and deeply on work in other disciplines may be needed to ensure that measures represent a well-grounded conceptualisation of TIG.

Thus, initial work on TIG has mostly conceptualised and measured TIG in terms of propositional beliefs about God (e.g., the belief that God is benevolent), rather than other cognitive states such as acceptance and assuming, or believing much "thinner" statements about God. Further, it has omitted what seems more central to TIG than cognition, namely a relying on God for something that matters to one. Conceptualizations of TIG that foreground these possible components might affect measures in new and interesting ways. Thus, as with any developing field of study, there is a need for strong theory that can help refine measurement and drive research.

\section{Drawing on interdisciplinary theory to conceptualise TIG}

Because the current conceptualizations of TIG in the psychology of religion focus mostly on beliefs about God, it is possible that TIG is conflated with conformance to theological ideology within a tradition or other constructs that have very little to do with TIG. Both of the main research teams that have conducted programmatic research on TIG conceptualised TIG mostly in terms of propositional beliefs about God-specifically, whether God has benevolent intentions. Given the strong correlations between these beliefs and other constructs, the study of TIG, from the very outset, faces a danger of reproducing prior work on similar constructs.

For example, to what degree are current measures, and future measures, of TIG simply indicative of religious orthodoxy? That is, most theistic traditions assert the benevolence of God, and research on TIG has been mostly cognitive-focused, assessing whether people believe certain things about God. Belonging to a group typically involves having these beliefs, and this is especially true within many Protestant Christian groups, which predominate in many US samples. So, again, responses to measures could conflate TIG with religious orthodoxy.

Religious orthodoxy could easily become conflated with TIG because interpreting scripture is a primary means of hearing from God within many groups. Yet, most groups rely on religious leaders and a broader tradition to put some limits on what people put their trust in God for. Pressures to conform to the beliefs of a community can be quite strong, and in cases of intratextual fundamentalism, religious groups may become closed off to influences outside the religious community or broader tradition (Hood et al., 2005; Williamson et al., 2010). 
This sort of challenge is precisely the kind of situation where it may prove helpful for psychologists to consider theory from a variety of disciplines before charting a course. We suggest a strategy that involves careful work to conceptualise TIG and test the measurement implications of that work at both the general (i.e., TIG) and specific (i.e., TIGx) level. Once the conceptual and measurement foundations are fortified, it would then make sense to examine predictors and outcomes of TIG, and researchers would have greater reason to expect that the endeavour would yield new insight rather than simply replicating prior work.

What are the core features of trust and TIG from a philosophical perspective, and how does this differ from the psychological conceptualizations we reviewed earlier? Since Baier (1986), theories of trust typically involve reliance as a core component, and then distinguish trust from mere reliance by some further features of trust. This suggests a conceptualisation of TIG that involves relational and behavioural factors (i.e., reliance), not just a cognitive factor or, more narrowly, a belief factor. Whether trust also involves belief remains a matter of disagreement among philosophers. In one class of theories, for you to trust someone to do something is, roughly, for you to (1) be disposed to rely on them to do it, and (2) expect that they will do it, which is a predictive rather than normative expectation. In another class of theories, for you to trust someone to do something is, roughly, for you to (1) be disposed to rely on them to do it, and (2) expect that they prima facie should do it, which is a normative rather than a predictive expectation (McKaughan \& Howard-Snyder, in preparation). This suggests that TIG involves two key factors: (1) relying on God to come through (i.e., relational/behavioural factor), and (2) a predictive and/or normative expectation that God will and/or prima facie should come through (i.e., cognitive factor).

The first relational/behavioural factor (i.e., relying on God to come through) is more consistent with the developmental theories mentioned above (i.e., Bowlby, 1968; Erikson, 1950) than purely cognitive conceptualizations of TIG. We should also mention that the disposition to rely on God is not arbitrary, but is formed on the basis of direct or indirect relational encounters that shape the disposition. While these shaping relational experiences are not an intrinsic part of the construct of TIG, their role should be noted, as they connect this construct with other constructs such as attachment to God.

As for the second cognitive factor, it is important to note that, when a person puts their trust in another person to do something, the required expectation might be belief, but it might also be some other cognitive state (e.g., acceptance or beliefless assuming), or it might be belief of a much "thinner" statement than that they will do it or that they prima facie should do it. Trust theorists in philosophy agree that the trustor cannot believe that the trusted will not or prima facie should not do it, but that leaves a lot of flexibility in the cognitive factor, a far cry from the insistence on belief that God is benevolent that we find in Rosmarin (Rosmarin et al., 2009) and Krause (2015a), for example.

Philosophical conceptualizations of trust also distinguish one-, two-, and three-place trust (McKaughan \& Howard-Snyder, in preparation). First, someone can be higher or lower in trust (i.e., one-place trust). In other words, they can be more or less likely to be a trusting person, someone who is more or less likely to trust others, including God, across situations and targets. Second, someone can have higher or lower levels of trust in a particular person (i.e., two-place trust), including God (TIG). Finally, someone can be 
higher or lower in trust in another person, in some capacity or to do something (i.e., threeplace trust). For example, they trust them to come through, as a student but not as a pilot, or they trust them to manage their personal finances but not to run an investment company. Applied to God (TIGX), someone with three-place trust might trust God as a loving and providential creator, but not as a plumber, or they might trust God to make all things well, but not to take out the garbage cans.

Based on this conceptualisation of TIG, we offer three key implications for future research.

\section{Implication 1: trusting behaviour evidences trust}

Can someone trust God without being disposed to engage in trusting behaviour? There is reason to expect that trust will at least typically have behavioural manifestations. For example, according to Pace (2020), trusting someone requires a willingness to take practical risks on their proving trustworthy and a level of confidence sufficient to motivate relevant actions even if that confidence falls far short of belief. When trusting in God, a person takes a risk and acts as though God will be involved and come through in the expected way. For a crude metaphor, imagine a chair with a broken leg. It is one thing to believe that the chair is still structurally sound enough to sit on, but it is an entirely different psychological state to rely on it by sitting on the chair. More work will be needed to measure this state well. Most likely, innovation will be needed in measurement and research design, because there are a variety of factors that indicate TIG. In some cases, the relevant behaviour may involve inaction (e.g., waiting on the Lord), or patient engagement of prayer or other spiritual disciplines until a person obtains a clearer sense of what to expect from God.

To ascertain someone's degree of TIG, according to this conceptualisation, we would need to ascertain more than someone's beliefs about God. Given that trust involves reliance, studies of TIG would do well to explore behaviours characteristic of relying on God. The primary evidence for TIG would involve several parts. First, we would need information about what people are relying on God for, including their expectations of God in situations where these have the potential to be upheld or violated. Second, we would need information about their behaviour, in situations where the person has variable options to respond, based on the degree to which they are relying on God to come through. Third, we might also want information about how people react when they take their expectations to have been upheld or violated. Each step involves a variety of beliefs or other cognitive states, motivations, emotions, and possible behaviours. So, the challenge for psychologists is to begin to-albeit crudely at first-develop ways to constrain some of the complexity in order to isolate aspects of TIG.

For example, what might be some behavioural indicators of TIG, or relying on God to come through? These behavioural indicators might vary based on religious affiliation and denomination or cultural background, but could include activities such as turning toward God in time of stress or adversity such as threats to one's health, finances, or concerns in one's family. It may also be demonstrated in rituals such as devotional or scriptural reading focusing on a general reliance on God. Petitionary prayer (i.e., asking God for something) or even asking others to pray for something may also be an indicator of TIG (Krause \& Hayward, 2013, 2014). Engaging in religious coping 
strategies (Pargament, 1997) in response to a stressful event may also be a behavioural indicator of TIG.

\section{Implication 2: psychologists need to study trust at varying levels of specificity}

As we indicated earlier, it is important to distinguish assessing the degree to which individuals trust God in general (TIG) from the degree to which they trust God in a particular capacity or trust God to act in a particular way (TIGX). Perhaps individuals who have a high degree of TIG also have a high degree of TIGx. Alternatively, perhaps individuals who have a high degree of TIG also have a high degree of one-place trust (generally). Initial work on TIG has only focused on something crudely related to two-place trust-namely, trusting God because of attributes, without attending to details, such as variations in what people expect of God, either predictively or normatively, and one's degree of confidence that God will live up to human expectations.

The goal of conceptualising and measuring specific instances of TIGx may need to be achieved before attempting to operationalise TIG, in order to distinguish TIG from similar constructs. This is particularly important in light of existing research showing strong correlations with variables such as intrinsic religiosity, which challenges the discriminant validity of current measures of TIG. A specific instance of TIGx will need to be identified in ways that are able to differentiate it from alternative explanations. For example, someone may report that they are trusting God to do something in a particular situation, while actually they are simply conforming to group norms in order to protect their social standing in their religious community. It may be that only after these specific instances of TIGx are identified, can a measure of a more trait-like or global TIG be constructed by aggregating several instances of TIGx. Identifying and studying specific instances of TIGx may also be important because trusting God in different instances may have differential effects on one's TIG more generally. For example, a person who trusts God for one consequential action (e.g., saving me from my sins) may look different from a person who trusts God for smaller actions throughout one's day.

\section{Implication 3: it is important to study how people form expectations of God and cope with disappointed expectations}

TIG - which crucially involves relying on God to come through-does not come without relational risk. When people count on God for things that matter a lot to them, they will have various predictive or normative expectations. Expectations about what God will or won't do, or should or shouldn't do, can be frustrated or violated. When their expectations are frustrated or violated, they might feel let down, disappointed, betrayed, or resentful. Similarly, they might feel gratitude when their expectations are upheld. The experience of frustrated or violated expectations might create uncertainty in one's relationship with God, or people might blame themselves for generating false expectations in the first place. Since the range of reactions people experience might correlate with the particularities of their theological commitments, it may be important to explore both how people come up with the expectations they place on God (e.g., are there individual, cultural, or religious predictors of these expectations?), as well as how people cope when their 
expectations are not met (e.g., does TIG persist, or does it decrease following unmet expectations?).

\section{Model of TIG and related constructs}

In this next section, we present a theorised model of the relationships between TIG (both general and specific), predictors of TIG, and outcomes of TIG (see Figure 1). Our model of TIG has cognitive, emotional, and motivational predictors, which suggests several fruitful avenues for further research. Here we discuss these as cognitive predictors of general TIG, affective predictors of general TIG, motivational predictors of general TIG, predictors of specific TIG, and predicted outcomes of general and specific TIG.

\section{Cognitive predictors of general TIG}

In our conceptualisation, we would place most of the prior constructs and measurement strategies of TIG in this category-of cognitive predictors of general TIG (e.g., those found in Rosmarin's measure; Rosmarin, Pirutinsky, Auerbach, et al., 2011). However, in line with what we proposed about TIG earlier, we would also place new constructs and measurement strategies in this category (e.g., those that would assess believing "thinner" statements about God rather than "thicker" ones).

In our model, all of these cognitive states focused on God would fall under cognitive predictors of TIG. Some commonly believed claims about God (e.g., that God is loving or all-powerful) are hypothesised to be related to greater degrees of TIG. Also, we expect that having positive beliefs about the existence of God would be related to higher levels of TIG. We also hypothesise that "thinner" claims about God may be related to greater degrees of TIG (e.g., even when it is questionable whether God is loving, there's a good enough chance to act on that assumption). Other less commonly believed claims about God (e.g., that God is distant or uninvolved in worldly affairs) are hypothesised to be related to lower degrees of TIG. However, this domain is only one set of predictors of TIG.

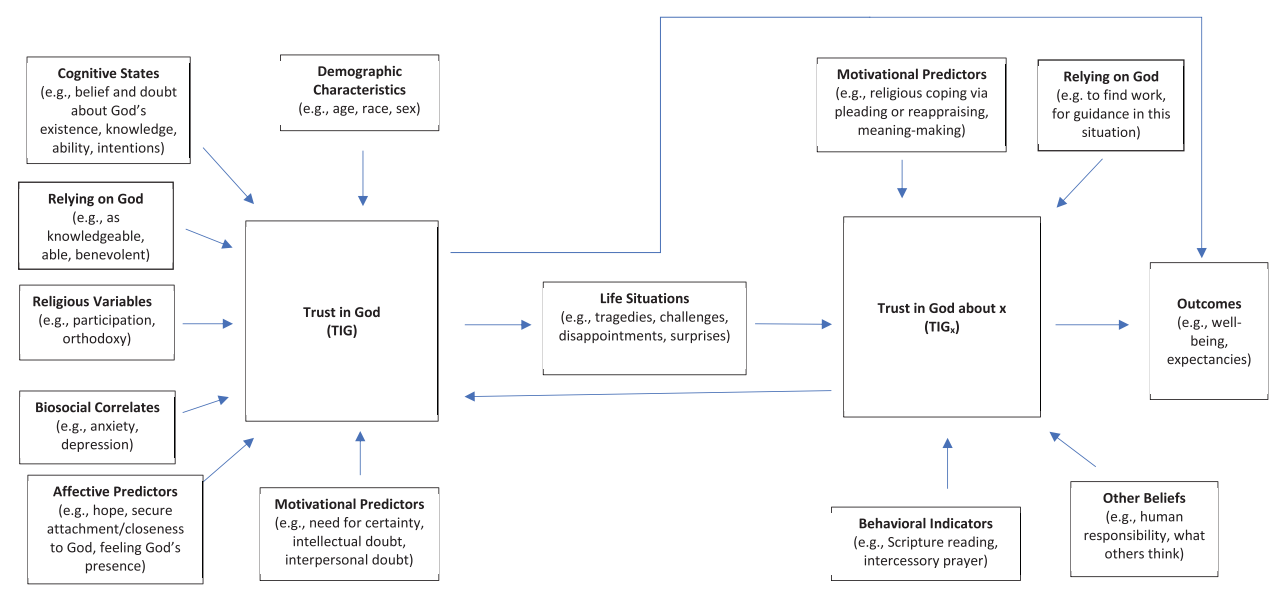

Figure 1. Conceptualizing the relationship of trust in God with predictors and outcomes. 


\section{Affective predictors of general TIG}

Existing research shows that the positive effect of trust in relationships may be more influenced by affect than cognition. For example, one study found that "deep acting" emotional labour in the workplace (i.e., regulation of feelings), but not "surface acting" (i.e., regulation of facial expressions), was influenced more by "affective trust" (i.e., trust conceptualised as emotional bonds between individuals) in servant leaders than "cognitive trust" (i.e., trust conceptualised as performance-relevant cognitions such as competence, responsibility, reliability, and dependability) (Lu et al., 2019; cf. McAllister, 1995). These results suggest that one may be more committed to a relationship when trust is rooted in strong affect. Of course, whether such findings translate to TIG is merely speculative at this point. However, Fadardi and Azadi (2017) found in a Muslim sample that positive affect was positively related to TIG, conceptualised as believing certain things about God and their relation to God; conversely, negative affect was negatively associated with their belief-focused construct of TIG. It might be interesting to assess whether doubt in combination with positive affect rather than doubt in combination with negative affect is more positively associated with TIG. Furthermore, it would be interesting to explore the relationship between feeling God's presence and TIG. In any case, it is likely important to consider affective and emotional predictors of TIG.

An especially fruitful area of research on TIG might be the close connections between TIG and attachment to God. There has been extensive work that has explored religion and one's relationship with God as an attachment system (Kirkpatrick, 2005). For example, religious individuals tend to (1) seek and maintain proximity to God, (2) use God as a safe haven in times of stress, (3) rely on God as a secure base from which to explore and develop, (4) respond to perceived separation from God with anxiety, and (5) perceive God as stronger and wiser than themselves (Davis et al., 2019; Granqvist et al., 2010). In one qualitative study of disaster survivors (Davis et al., 2019), when asked about their attachment behaviours to God, participants explicitly talked about actively putting their trust in God. It may be that having a secure attachment relationship with God leads to higher levels of TIG (and vice versa). Given that trust is a central component to relationships, focusing more on the affective and relational components of one's engagement with God should prove useful for advancing research on TIG.

\section{Motivational predictors of TIG}

Motivational factors may also predict TIG. Krumrei et al. (2013) noted that persons with an intrinsic religious motivation, where religion serves as a master-motive end in itself, are more inclined to TIG, conceived solely as beliefs about God, than are those extrinsically motivated individuals who see religion as a means to some other personal or social end. Does TIG, so conceived, reflect only the "mature sentiment" of intrinsically motivated religion (Allport, 1950)? Why might not an extrinsic motivation toward religion predict TIG just as well? Similarly, individuals with a strong need for meaning require a sense of purpose, self-worth, value, or efficacy (see Baumeister, 1991). Such personal needs for meaning may be associated with TIG. For example, resting assured that all of life has meaning and purpose, even in the face of tragedy, may require a trust in God who is sovereign over all things and who does all things well (Hood et al., 2005). 
A related motivational construct is one's need for the certainty that religion may provide. Indeed, compensatory control theories of religion posit that when feeling a lack of control or certainty, people turn to external structures, such as God, to restore a sense of control (Kay et al., 2010). At first glance, need for certainty may be positively associated with TIG. However, TIG might be more evident in the face of intellectual doubt or uncertainty. Ironically, it may require a greater trust in God when belief-cancelling doubt is present, and one nevertheless acts on the assumption that God is trustworthy.

The relationship of doubt to TIG may be more complex than studies of TIG in psychology of religion seem to presuppose. Though not directly measuring TIG, the empirical literature has quite consistently shown that higher levels of doubt are at least moderately associated with less religiousness such as Christian orthodoxy, less dogmatism, and lower intrinsic religiosity (Hunsberger et al., 1993; Hunsberger et al., 1996). However, research in this area has failed to distinguish intellectual doubt (i.e., lack of certainty about specific propositions; e.g., being in doubt about whether God is loving) from interpersonal doubt (i.e., lacking confidence in a person; e.g., feeling insecurity about God's love for me) (cf. Hall, 2021). TIG may be related in different ways to intellectual and to interpersonal doubt. Quest religious orientation-especially the distinction between "hard" quest and "soft" quest (Edwards et al., 2011)—might also be relevant to the relationship between doubt and TIG. Whether and, if so, how doubt is related to TIG has not been empirically tested.

\section{Predictors of specific TIG (TIGX)}

As already noted, two-place TIG (trust in God across time and situations) may differ from three-place TIGx (trusting God at some particular time for some particular thing, $x$ ). TIG is likely positively correlated with TIGx, perhaps even necessary for TIGx; and enough positive (or negative) TIGx experiences may promote (or hinder) TIG. Still, the association between TIG and TIGx may not be as strong as one might expect. For example, additional factors might differentially predict TIGx from a more general TIG (e.g., beliefs about human responsibility such as "There is no reason to trust that God will help me on this important exam if I don't do my part and study hard") and social support or lack thereof (e.g., "My friends think I am crazy to just trust God to take care of the matter"). Further, the consensual validation of church attendance and spiritual support as a predictor of TIG (Krause, 2015b) may even more robustly predict TIGx.

One way in which social support may encourage TIGx is through intercessory prayer. Though no scientifically discernible effect of intercessory prayer on physical health has been found (Masters et al., 2006), many people believe in the efficacy of prayer. Thus, we encourage further research that builds on the work of Krause and Hayward's (2013, 2014) TBPE. At the least, the effects of intercessory prayer on trust-related human relationships appears to be substantial, especially in close relationships. For example, praying for a romantic partner increases relationship satisfaction (Fincham et al., 2008) and relationship commitment (Fincham \& Beach, 2014) for both parties involved. Such prayer support may also impact TIGx simply by a reinforcing connection with others who demonstrate TIG.

Just as there are motivational factors of TIG, a motivational account of TIGx might be important in situations in which meaning and control are in jeopardy, such as conditions 
that we are unable to master or make sense of. Hood et al. (2018) point out that religion in general provides a greater sense of control in three forms: interpretive control ("things could be much worse"), predictive control ("things will turn out all right in the end"), and vicarious control ("let go and let God") when a situation, such as a life-threatening disease, is beyond one's control. TIGx may be an important component of religious coping with particular stressful life events. Pargament et al. (2001) discuss various ways that religion may be used to cope, many of which indicate a degree of TIGx such as benevolent religious reappraisal (e.g., "God gives me these trials to test me."), pleading religious coping (e.g., "Please, God, help me through this terrible time."), reappraisal of God's powers (e.g., "Nothing is too small for God not to notice and help."), and spiritual discontent (e.g., "How could God do this to me?").

The potential conflict between TIG and TIGx in these kinds of situations is illustrated in the body of research associated with Park's (2010) meaning-making model. According to this theory, which has robustly included religious constructs, when people face difficult circumstances, their distress can be predicted by the discrepancy between their global beliefs (that might predict TIG), and their initial appraisal of the difficult situation (which might predict TIGX). Often people have to go through a lengthy meaningmaking process in order to resolve discrepancies between these global and situational meanings. In the face of a life-threatening illness, for example, an individual may generally endorse TIG, but may still struggle to reconcile notions of God's trustworthiness in general with confidence that God will still be good in whatever the outcome of the illness may be. Such doubts may give rise to religious and spiritual struggles, which may alter their view of God (Van Tongeren, Sanders, et al., 2019).

\section{Predicted outcomes of TIG and TIGX}

To date, the research on correlates of TIG that might be conceptualised as outcomes (i.e., consequences of $\mathrm{TIG}$ ) has focused primarily on well-being. Although such research is important and should be further pursued, there may be other important outcome variables to consider, as well as variables that may serve as mediating variables to wellbeing. For example, do people who TIG display a more (or less) eudemonic sense of well-being? Do people engage in TIG for primarily selfish reasons (e.g., healing for oneself or loved one; hoping for a desirable new job)? Are there more altruistic ways to engage in TIG, where one's self-interest is deemphasized? Or is TIG another expression of self-focused processes that predominate in the social psychological literature?

Other outcome variables of interest may include the relationship between TIG and TIGx with perceptions of God in the face of tragedy, whether experienced personally or not. What role do TIG and TIGx play in questions of theodicy and how people make sense of suffering? For example, if people trust in God and view God as good, and yet watch their loved one suffer with a terminal disease, might they feel abandoned by, overlooked by, or angry at God? Or if they trust God to heal their family member and God does not, how might that affect their coping with loss and grief? Relatedly, how do TIG and TIGx influence perceptions of whether or not prayer requests have been answered? Not only are TBPEs different for those high in TIGx, but what criteria are used in determining whether those expectancies have been fulfilled? 
What happens when one perceives that TIG expectancies have been violated or ignored by God? Under what conditions does this lead to a mistrust in God (MIG)? Do violations of TIG expectancies produce doubt in God's sovereignty or character, or might TIG actually increase in the face of such struggles? How might TIGx be related to religious coping or spiritual fortitude (Van Tongeren, Sanders, et al., 2019)?

\section{Directions for future research}

Based on our conceptual model of TIG, there are several exciting areas for future research. First, it may be interesting to consider how well the measurement strategies offered by Rosmarin (Rosmarin et al., 2009) and Krause (2015a), based on their theoretical conceptualizations, get at the core aspects of TIG. Namely, both measurement strategies focus mainly on beliefs about the nature of God. As seen in our conceptualisation and model, perhaps these cognitive factors would be better placed as predictors of TIG rather than viewed as TIG itself. New measures may be necessary to get at the core aspects of TIG-which focus on (1) relying on God to come through and (2) having predictive and/or normative expectations that God will come through. Similarly, future work needs to differentiate TIG from other related constructs (e.g., religious orthodoxy, God representations).

It may also be important to question whether the existing measurement strategies are valid for individuals from different religious groups. Rosmarin has argued that although the development of his measurement strategy was rooted in Jewish theology, his items may be applicable to persons from other religious traditions as well (e.g., Christians and Muslims) (Rosmarin, Pirutinsky, \& Pargament, 2011). Indeed, there is initial evidence to support the reliability of his measure in these populations. However, it is uncertain whether a specifically Christian or a specifically Muslim theory of TIG may have led to different items or a different scale. There have also not yet been any attempts (to our knowledge) to apply Rosmarin's theory and measurement strategy (Rosmarin et al., 2009) to individuals outside the Abrahamic religions, or for individuals who engage in Eastern religious practices, polytheistic religions, or non-religious spiritualities. Similarly, the majority of Krause's studies on TIG have focused on Christians (e.g., Krause, 2015a, 2015b). It is uncertain whether his conceptualisation of TIG would apply to people from other religious traditions. And, of course, within each of these major traditions, there is great variety. Certainly, a robust theoretical framework of TIG should include a consideration of how various religious traditions and sub-traditions-including those that place multiple deities at the centre of their religious focus-conceptualise TIG.

Second, future work could further explore the similarities and differences between TIG and MIG. Rosmarin and colleagues have suggested that TIG and MIG are getting at different constructs-TIG reflects a basic presence or absence of core beliefs about God, whereas MIG is more connected with spiritual struggle (Rosmarin, Pirutinsky, Auerbach, et al., 2011). However, the empirical data show very similar correlations (in opposite directions) between TIG, MIG, and related constructs. A compelling alternative hypothesis that would need to be accounted for is that the difference between TIG and MIG is method variance: negatively worded items are often clustered on one factor and positively worded items on another factor; rather than reflecting two different psychological dimensions or constructs, they rather reflect valence in a self-report measure. It remains to 
be seen whether TIG and MIG are conceptually unique, or whether they reflect a similar underlying phenomenon.

Third, future research could further examine the relationship between TIG and religious coping. One previous research study found that TIG was positively related to positive religious coping and negatively related to negative religious coping (Krumrei et al., 2013). (The opposite pattern was found for MIG.) However, this study used a brief measure of religious coping that divided religious coping into two categories: positive and negative. It would be interesting to explore the relationship between TIG and specific religious coping strategies, such as collaborative religious coping and passive religious deferral (Pargament et al., 2000)

Fourth, future research could investigate potential differences between trust and faith, whether constructs related to TIG and faith in God (FIG) are empirically distinguishable, and whether one or the other more usefully tracks psychological features salient to religious life and practice. For example, some accounts of FIG differentiate it from TIG by focusing on the importance of resilience in the face of challenges (McKaughan \& Howard-Snyder, in preparation). In other words, FIG may be particularly helpful when individuals experience challenges or struggles in their religious journey. Studies investigating the relations between either FIG or TIG and resilience and other questions, such as the extent to which either construct is compatible with intellectual doubt, might explore how these constructs manifest over time, especially through various kinds of challenges and difficulties.

Fifth, future work might also pursue differences and similarities between trust and trustworthiness, and faith and faithfulness. This is especially important given the prevalence and importance of relationships of mutual faith and faithfulness both in human life and in the covenantal relationships between God and human beings in Abrahamic religions as these are understood in recent biblical, historical, and theological work (Bates, 2020; Lindsay, 1993; Morgan, 2015). On the face of it, when a person puts their faith in God, they are disposed to rely on God for whatever it is that they put their faith in God for. Typically, however, they also take it that God relies on them to come through in a variety of ways - perhaps because God has entrusted to them the care of creation or more specific vocations - and, when they do come through in these ways, their doing so can be usefully conceptualised as resulting from their being faithful to God with respect to what they take God to be relying on them for. Faith is not faithfulness (McKaughan \& Howard-Snyder, in press) - and so a rich research programme in the psychology of religion awaits, one that involves conceptualising faithfulness to God, developing measures of it, and relating it to faith and other nearby constructs as well as a host of other outcomes (e.g., behaviour and well-being).

Sixth, research might study exemplars of faith and faithfulness. It is one thing to conceptualise faith as a complex mental state; it is quite another to conceptualise it as something more trait-like; and it is a third thing to conceptualise it as a moral and/or intellectual excellence. Just as psychologists have studied geniuses and exceptional leaders, and just as psychologists have begun to study morally exceptional people, so they might study exemplars of faith and faithfulness generally, as well exemplars of faith in and faithfulness to God. Different religious traditions will put forward different historically prominent exemplars (e.g., Abraham and Jesus, as well as more recent ones such as Mother Teresa; McKaughan, 2018). Study of these and other people might provide a template for conceptualising faith and faithfulness as excellences, which might then 
enable psychologists to identify living people who are exemplars of these traits. Study of these living individuals may well turn up features and practices that might help others as they aim to live well within their religious tradition.

\section{Practical application}

TIG may be an important construct to consider for therapists or religious leaders who are working with individuals who are struggling with mental health problems or their relationship with God. If individuals are struggling with TIG, it may be helpful to discuss in more detail what they are trusting God for. In other words, does TIG refer to more of a general tendency to rely on God? Or does TIG refer to relying on God for something specific-either in a particular capacity or for a particular action? It may be that a more general reliance on God is more beneficial for mental health than trusting God to intervene on specific issues or events. Perhaps, for some, simply trusting God in general without qualifications or expectations regarding how God ought to act would provide freedom and comfort when life eludes easy explanation or simplistic answers.

TIG could also be a religious variable that can help people manage a stressful situation, thus mitigating the negative effects of stress and adversity. If someone is going through a difficult time, it might be helpful to discuss with them how TIG might help them withstand the challenge, similar to the idea of using spiritual fortitude to engage one's struggles or obstacles in a productive manner (Van Tongeren, Aten, et al., 2019). However, we hasten to clarify that for some undergoing religious and spiritual struggle, the idea of encouraging TIG may feel invalidating and inauthentic; for some, trusting God may be precisely what led to their strugglesespecially if they assume that TIG requires belief. Thus, we encourage wise clinical insight regarding the nature of the struggle and history and beliefs of the particular client.

One way that R/S might positively impact health is by giving religious individuals access to a wide array of R/S-specific coping resources, such as prayer, meditation, and social support (Pargament, 1997). It may be that TIG enables individuals to utilise a broad range of $\mathrm{R} / \mathrm{S}$ coping resources that are available to them. In fact, utilising religious coping strategies might be one behavioural manifestation of relying on God. If religious individuals are struggling with stressful events, it may be helpful to reorient them toward TIG and the R/S coping resources that have worked for them in the past.

Finally, given the growing number of people who are leaving religion (i.e., the rise of the "nones;" Pew-Templeton, n.d.) via deidentification, disaffiliation, or deconversion, a better understanding of the role of TIG in why people are walking away from faith is needed. Does an overly cognitive conceptualisation of TIG that equates TIG with belief, or sometimes even intellectual certainty and freedom from doubt, lead some who experience spiritual struggles to wonder if they really trust God at all, subsequently leading to a perceived loss of religious identity, and leaving one's religious community altogether? Might a more nuanced picture of TIG change the landscape of religious identities?

\section{Conclusion}

In the present article, we explored TIG from a psychological perspective. Similar to advances in theology and philosophy, psychologists have become more interested and active in studying TIG in recent years. Continued work in this area will help to develop a deeper and richer 
conceptualisation of TIG, distinguish it from nearby constructs such as FIG, clarify and improve existing measurement strategies, and further explore the effect of TIG on mental health and well-being. We hope this paper provides an impetus for such continued research.

\section{Acknowledgments}

We are grateful to Matthew Bates, Lara Buchak, Andrew Chignell, Oliver Crisp, Katherine Dormandy, Lindsay Driediger-Murphy, Julie Exline, Paul Faulkner, Judy Gundry, Elizabeth Krumrei-Mancuso, Teresa Morgan, Michael Pace, Benjamin Schliesser, and Thomas Simpson for conversation and comments on earlier drafts of this paper.

\section{Disclosure statement}

No potential conflict of interest was reported by the author(s).

\section{Funding}

This work was funded by a grant from the John Templeton Foundation (\#61106). The opinions expressed in this publication are those of the authors and might not reflect the views of the John Templeton Foundation.

\section{References}

Allport, G. W. (1950). The individual and his religion. Macmillan.

Alston, W. P. (1996). Belief, acceptance, and religious faith. In J. Jordan, \& D. Howard-Snyder (Eds.), Faith, freedom, and rationality (pp. 3-27, 241-244). Rowman \& Littlefield.

Baier, A. (1986). Trust and antitrust. Ethics, 96(2), 231-260. https://doi.org/10.1086/292745

Bates, M. W. (2020). The external-relational shift in faith (pistis) in New Testament research: Romans 1 as Gospel-allegiance test case. Currents in Biblical Research, 18(2), 176-202. https://doi.org/10. $1177 / 1476993 \times 19889213$

Baumeister, R. F. (1991). Meanings of life. Guilford Press.

Bowlby, J. (1968). Attachment and loss, Vol. 1: Attachment. Basic Books.

Cohen, A. B. (2009). Many forms of culture. American Psychologist, 64(3), 194-204. https://doi.org/10. 1037/a0015308

Davis, E. B., Kimball, C. N., Aten, J. D., Hamilton, C., Andrews, B., Lemke, A., Hook, J. R., Captari, L., Granqvist, P., Hook, J. N., Davis, D. E., Van Tongeren, D. R., Cattrell, E. L., Cuthbert, A. D., \& Chung, J. (2019). Faith in the wake of disaster: A longitudinal qualitative study of religious attachment following a catastrophic flood. Psychological Truama: Theory, Research, Practice, and Policy, 11(6), 578-587. https://doi.org/10.1037/tra0000425

Edwards, K. J., Hall, T. W., Slater, W., \& Hill, J. (2011). The multidimensional structure of the quest construct. Journal of Psychology and Theology, 39(2), 87-110. https://doi.org/10.1177/ 009164711103900201

Erikson, E. H. (1950). Childhood and society. Norton.

Fadardi, J. S., \& Azadi, Z. (2017). The relationship between trust-in-God, positive and negative affect, and hope. Journal of Religion and Health, 56(3), 796-806. https://doi.org/10.1007/s10943-015-0134-2

Faulkner, P., \& Simpson, T. W. (Eds.). (2017). The philosophy of trust. Oxford University Press.

Fincham, F. D., \& Beach, S. R. H. (2014). I say a little prayer for you: Praying for partner increases commitment in romantic relationships. Journal of Family Psychology, 28(5), 587-593. https://doi.org/ 10.1037/a0034999 
Fincham, F. D., Beach, S. R. H., Lambert, N., Stillman, T., \& Braithwaite, S. R. (2008). Spiritual behaviors and relationship satisfaction: A critical analysis of the role of prayer. Journal of Social and Clinical Psychology, 27(4), 362-388. https://doi.org/10.1521/jscp.2008.27.4.362

Garssen, B., Visser, A., \& Pool, G. (2021). Does spirituality or religion positively affect mental health? Meta-analysis of longitudinal studies. The International Journal for the Psychology of Religion, 1(1), 4-20. https://doi.org/10.1080/10508619.2020.1729570

Godfrey, J. J. (2012). Trust of people, words, and God: A route for philosophy of religion. University of Notre Dame Press.

Granqvist, P., Mikulincer, M., \& Shaver, P. R. (2010). Religion as attachment: Normative processes and individual differences. Personality and Social Psychology Review, 14(1), 49-59. https://doi.org/10. $1177 / 1088868309348618$

Hafizi, S., Rosmarin, D. H., \& Koenig, H. G. (2014). Brief Trust/Mistrust in God Scale: Psychometric properties of the Farsi version in Muslims. Mental Health, Religion \& Culture, 17(4), 415-420. https://doi.org/10.1080/13674676.2013.816942

Hall, M. E. L. (2021). Teaching students to doubt well: The roles of intellectual humility and uncertainty tolerance. Christian Scholars Review, 50(3), 261-279.

Hill, P. C., \& Pargament, K. I. (2003). Advances in the conceptualization and measurement of religion and spirituality: Implications for physical and mental health research. American Psychologist, 58(1), 64-74. https://doi.org/10.1037/0003-066X.58.1.64

Hood, Jr., R. W., Hill, P. C., \& Spilka, B. (2018). The psychology of religion: An empirical approach (5th ed.). Guilford Press.

Hood, Jr., R. W., Hill, P. C., \& Williamson, W. P. (2005). The psychology of religious fundamentalism. Guilford Press.

Hook, J. N., Worthington, Jr., E. L., \& Davis, D. E. (2012). Religion and spirituality in counseling. In N. A. Fouad, J. A. Carter, \& L. M. Subich (Eds.), APA handbooks in psychology: APA handbook of counseling psychology, Vol. 2 (pp. 417-432). American Psychological Association.

Howard-Snyder, D. (2017). The skeptical Christian. Oxford Studies in Philosophy of Religion, 8, 142-167.

Hunsberger, B., Alisat, S., Pancer, S. M., \& Pratt, M. (1996). Religious fundamentalism and religious doubts: Content, connections, and complexity of thinking. The International Journal for the Psychology of Religion, 6(3), 201-220. https://doi.org/10.1207/s15327582ijpr0603_7

Hunsberger, B., McKenzie, B., Pratt, M., \& Pancer, S. M. (1993). Religious doubt: A social psychological analysis. Research in the Social Scientific Study of Religion, 5, 27-51.

Ibn Pekuda, B. (1996). Duties of the heart. (Y. Feldman, Trans.). Jason Aronson. (Original work published circa 1080).

Kay, A. C., Gaucher, D., McGregor, I., \& Nash, K. (2010). Religious belief as compensatory control. Personality and Social Psychology Review, 14(1), 37-48. https://doi.org/10.1177/1088868309353750

Kirkpatrick, L. A. (2005). Attachment, evolution, and the psychology of religion. Guilford Press.

Krause, N. (2004). Assessing the relationships among prayer expectancies, race, and self-esteem in late life. Journal for the Scientific Study of Religion, 43(3), 395-408. https://doi.org/10.1111/j.14685906.2004.00242.x

Krause, N. (2015a). Trust in god and psychological distress: Exploring variations by religious affiliation. Mental Health, Religion \& Culture, 18(4), 235-245. https://doi.org/10.1080/13674676.2015. 1021311

Krause, N. (2015b). Trust in god, forgiveness by god, and death anxiety. OMEGA-Journal of Death and Dying, 72(1), 20-41. https://doi.org/10.1177/0030222815574697

Krause, N., Chatters, L. M., Meltzer, T., \& Morgan, D. L. (2000). Using focus groups to explore the nature of prayer in late life. Journal of Aging Studies, 14(2), 191-212. https://doi.org/10.1016/ S0890-4065(00)80011-0

Krause, N., \& Hayward, R. D. (2013). Prayer beliefs and change in life satisfaction over time. Journal of Religion and Health, 52(2), 674-694. https://doi.org/10.1007/s10943-012-9638-1

Krause, N., \& Hayward, R. D. (2014). Trust-based prayer expectancies and health among older Mexican Americans. Journal of Religion and Health, 53(2), 591-603. https://doi.org/10.1007/ s10943-013-9786-y 
Krause, N., \& Hayward, R. D. (2015). Assessing whether trust in God offsets the effects of financial strain on health and well-being. The International Journal for the Psychology of Religion, 25(4), 307-322. https://doi.org/10.1080/10508619.2014.952588

Krumrei, E. J., Pirutinsky, S., \& Rosmarin, D. H. (2013). Jewish spirituality, depression, and health: An empirical test of a conceptual framework. International Journal of Behavioral Medicine, 20(3), 327336. https://doi.org/10.1007/s12529-012-9248-z

Lindsay, D. R. (1993). The roots and development of the miot- word group as faith terminology. Journal for the Study of the New Testament, 49(49), 103-118. https://doi.org/10.1177/ $0142064 X 9301504907$

Lu, J., Zhang, Z., \& Jia, M. (2019). Does servant leadership affect employees' emotional labor? A social-information processing perspective. Journal of Business Ethics, 159(2), 507-518. https:// doi.org/10.1007/s10551-018-3816-3

Masters, K. S., Spielmans, G. I., \& Goodson, J. T. (2006). Are there demonstrable effects of intercessory prayer?: A meta-analytic review. Annals of Behavioral Medicine, 32(1), 21-26. https://doi.org/10. 1207/s15324796abm3201_3

McAllister, D. J. (1995). Affect- and cognition-based trust as foundations for interpersonal cooperation in organizations. Academy of Management Journal, 38, 24-59. https://doi.org/10. 2307/256727

McKaughan, D. J. (2018). Faith through the dark of night. Faith and Philosophy, 35(2), 195-218. https://doi.org/10.5840/faithphil2018327101

McKaughan, D. J., \& Howard-Snyder, D. (in preparation). How does trust relate to faith?

McKaughan, D. J., \& Howard-Snyder, D. (in press). Theorizing about faith and faithfulness with Jonathan Kvanvig. Religious Studies.

Morgan, T. (2015). Roman faith and Christian faith: Pistis and fides in the early Roman empire. Oxford University Press.

Oman, D., \& Syne, S. L. (2018). Weighing the evidence: What is revealed by $100+$ meta-analyses and systematic reviews of religion/spirituality and health? In D. Oman (Ed.), Why religion and spirituality matter for public health: Evidence, implications, and resources (pp. 261-281). Springer.

Pace, M. (2020). Trusting to inspire trustworthiness. Synthese. Advance online publication. https:// doi.org/10.1007/s11229-020-02840-8

Pargament, K. I. (1997). The psychology of religion coping: Theory, research, and practice. Guilford Press.

Pargament, K. I., Koenig, H. G., \& Perez, L. M. (2000). The many methods of religious coping: Development and initial validation of the RCOPE. Journal of Clinical Psychology, 56(4), 519-543. https://doi.org/10.1002/(SICI)1097-4679(200004)56:4<519::AID-JCLP6>3.0.CO;2-1

Pargament, K. I., Poloma, M. M., \& Tarakeshwar, N. (2001). Methods of coping from the religions of the world: The bar mitzvah, karma, and spiritual healing. In C. R. Snyder (Ed.), Coping with stress: Effective people and processes (pp. 259-284). Oxford University Press.

Park, C. L. (2010). Making sense of the meaning literature: An integrative review of meaning making and its effects on adjustment to stressful life events. Psychological Bulletin, 136(2), 257-301. https://doi.org/10.1037/a0018301 doi:10.1037/a0018301

Pew-Templeton. (n. d.). Global religious futures project. http://www.globalreligiousfutures.org/

Rodriguez, L. M., DiBello, A. M., Øverup, C. S., \& Neighbors, C. (2015). The price of distrust: Trust, anxious attachment, jealousy, and partner abuse. Partner Abuse, 6(3), 298-319. https://doi.org/ 10.1891/1946-6560.6.3.298

Rosmarin, D. H., Pargament, K. I., \& Mahoney, A. (2009). The role of religiousness in anxiety, depression, and happiness in a Jewish community sample: A preliminary investigation. Mental Health, Religion \& Culture, 12(2), 97-113. https://doi.org/10.1080/13674670802321933

Rosmarin, D. H., Pargament, K. I., Pirutinsky, S., \& Mahoney, A. (2010). A randomized controlled evaluation of a spiritually integrated treatment for subclinical anxiety in the Jewish community, delivered via the internet. Journal of Anxiety Disorders, 24(7), 799-808. https://doi.org/10.1016/j.janxdis.2010.05.014

Rosmarin, D. H., Pirutinsky, S., Auerbach, R. P., Bjorgvinsson, T., Bigda-Peyton, J., Andersson, G., Pargament, K. l., \& Krumrei, E. J. (2011). Incorporating spiritual beliefs into a cognitive model of worry. Journal of Clinical Psychology, 67(7), 691-700. https://doi.org/10.1002/jclp.20798 
Rosmarin, D. H., Pirutinsky, S., \& Pargament, K. I. (2011). A brief measure of core religious beliefs for use in psychiatric settings. International Journal of Psychiatry in Medicine, 41(3), 253-261. https:// doi.org/10.2190/PM.41.3.d

Rowatt, W., \& Kirkpatrick, L. A. (2002). Two dimensions of attachment to God and their relation to affect, religiosity, and personality constructs. Journal for the Scientific Study of Religion, 41(4), 637-651. https://doi.org/10.1111/1468-5906.00143

Saroglou, V. (2011). Believing, bonding, behaving, and belonging: The big four religious dimensions and cultural variation. Journal of Cross-Cultural Psychology, 42(8), 1320-1340. https://doi.org/10. $1177 / 0022022111412267$

Simmel, G. (1964). The sociology of Georg Simmel. (K. H. Wolff, Trans.). Free Press.

Sue, D. W., Arredondo, P., \& McDavis, R. J. (1992). Multicultural counseling competencies and standards: A call to the profession. Journal of Counseling and Development, 70(4), 477-486. https://doi. org/10.1002/j.1556-6676.1992.tb01642.x

Van Tongeren, D. R., Aten, J. D., McElroy, S., Davis, D. E., Shannonhouse, L., Davis, E. B., \& Hook, J. N. (2019). Development and validation of a measure of spiritual fortitude. Psychological Trauma: Theory, Research, Practice, and Policy, 11(6), 588-596. https://doi.org/10.1037/tra0000449

Van Tongeren, D. R., Sanders, M., Edwards, M., Davis, E. B., Aten, J. D., Ranter, J. M., Tsarouhis, A., Short, A., Cuthbert, A., Hook, J. N., \& Davis, D. E. (2019). Religious and spiritual struggles alter God representations. Psychology of Religion and Spirituality, 11(3), 225-232. https://doi.org/10.1037/rel0000173

Williamson, W. P., Hood, Jr., R. W., Ahmad, A., Sadiq, M., \& Hill, P. C. (2010). The Intratextual Fundamentalism Scale: Cross-cultural application, validity evidence, and relationship with religious orientation and the big 5 factor markers. Mental Health, Religion \& Culture, 13(7-8), $721-$ 747. https://doi.org/10.1080/13674670802643047 